\title{
ANALYSIS OF CURRENT INTENSIFICATION IN THE NORTHWEST MEDITERRANEAN SHELF
}

\author{
M. Mestres ${ }^{1,2, \dagger}$, M. Grifoll ${ }^{1,2}$ and A. Sánchez-Arcilla ${ }^{1,2}$ \\ ${ }^{1}$ Laboratori d’Enginyeria Marítima, Universitat Politécnica de Catalunya BarcelonaTech, Jordi \\ Girona 1-3, Mòdul D1, Campus Nord, 08034 Barcelona, Spain. mmestresridge@gmail.com; \\ manel.grifoll@upc.edu; agustin.arcilla@upc.edu. \\ ${ }^{2}$ International Centre for Coastal Resources Research (CIIRC), Jordi Girona 1-3, Mòdul D1, \\ Campus Nord, 08034 Barcelona, Spain.
}

\begin{abstract}
Flow intensification episodes lasting more than 12 hours are observed occasionally at different locations along the Nortwestern Mediterranean coast. In the last years, these pulses have hindered ship operations outside the Barcelona harbour, thus attracting the attention of the port authorities. In this paper, the strongest intensification events in the Barcelona coast area are quantified and characterized in order to identify the mechanisms which generate them. For this, current, sea level and meteorological measured and modelled data, at local and regional scale, are analyzed. The results show that the flow accelerations are due to the combination of a narrow coastal shelf and the prevalence of a strong and sustained wind from the NE to SE. The synoptic atmospheric conditions that lead to this meteorological scenario are described. For one of the events, the presence and contribution to the current fluctuations of a coastal trapped wave, likely generated at the Eastern edge of the Gulf of Lions shelf, and other factors such as a freshwater discharge are also identified and discussed.
\end{abstract}

KEYWORDS: Northwestern Mediterranean; Current pulses; Shelf narrowing; Coastal Trapped Wave.

\section{HIGHLIGHTS:}

- Occasional flow intensifications on the NW Mediterranean shelf are analysed

- Main causes are sustained winds from the NE-SE combined with the shelf narrowing

- Sporadic presence of coastal trapped waves is found, and contributes to flow pulses

- $\quad$ Link between pulses and climatic indices suggests further increase of pulse occurrence

\section{1.- INTRODUCTION}

Traditionally, the scientific and engineering interests on the hydrodynamics of a specific region has been focused on the mean hydrodynamic behaviour, but the importance of local ("extreme") current pulses cannot be ignored. Strong current events are of concern for maritime industries

\footnotetext{
${ }^{\dagger}$ Corresponding autor: mmestresridge@gmail.com
} 
such as gas and oil related activities (Ivanov and Magnell, 2012), aquaculture practices (Kumar and Karnatak, 2014) or harbour operativeness (Sánchez-Arcilla et al., 2010). The coupling of meteorological phenomena and local topographic features are also a probable source for flow pulses. Locally energetic or persistent wind events with a strong alongshore component lead to Ekman transport of surface water, thus enhancing (or dampening) the underlying currents. The combination of atmospheric pressure gradients and winds might generate strong storm surges, with an evident increase of the coastal water motion.

Intense water flows have been observed at different locations along the Catalan coast (NW Mediterranean Sea), usually associated to strong local wind events (e.g., Palanques et al., 2002; Jordà, 2005; Grifoll et al., 2015), even during energetic events the depth-averaged current magnitudes do not exceed $50 \mathrm{~cm} / \mathrm{s}$. However, and coinciding with the southward development of the Barcelona harbour (Figure 1), the Port Authority has become aware during the last years of the existence of occasional current intensification episodes near the south port mouth that can hinder the manoeuvrability, approach and entrance of ships into the harbour through this access.

The presence of a permanent southwestward slope current is modulated on the shallowest part of the shelf by numerous physical processes at different temporal and spatial scales, including wind-forced motion (Grifoll et al., 2012), density-driven currents (Liste et al., 2014) and the propagation of barotropic long waves (Jordi et al., 2005). The inner and mid-shelf shelf circulation is characterized by a marked seasonal variability due to the heat and freshwater fluxes and the wind characteristics (Grifoll et al., 2013). Low-frequency motion in this region is controlled essentially by frictional forcing (wind and bottom stresses) and pressure gradients (both barotropic and baroclinic) in shallower waters, and by inertial-scale processes in the outer shelf (Palanques et al., 2002; Grifoll et al., 2012, 2013; Liste et al., 2014). However, Grifoll et al. (2012, 2013) suggest an eventual prevalence of the remote forcing -associated to regional bathymetric features or to the spatial gradients of wind and atmospheric pressure - in water motion but they did not clarify its link with the short-term current intensification (i.e. order of few days).

Following the concern of the Barcelona Port Authority with strong flow events sporadically observed near the south harbour mouth, Espino et al. (2011) undertook a first analysis of these currents, correlating three intensification events with local wind and wave forcings. They found a clear connection between the speed and direction of the wind and those of the currents, and attributed the flow intensification to the enhanced transfer of energy to the top water layers during long and intense wind periods.

The goal of this paper is to go a step further using the output from numerical models and oceanographic and meteorological field data, recorded during a three-year period near the south entrance of the Barcelona harbour and along the Northwestern Mediterranean coast. With this, we aim to characterize and quantify these flow intensifications, and shed some light on their probable causes, local or remote.

\section{2.- STUDY ZONE}


In the northmost Spanish Mediterranean coast in which Barcelona is located, the general circulation pattern presents a relatively complex pattern largely determined by the bottom bathymetry (Sánchez-Arcilla and Simpson, 2002). Particularly important are the characteristics of the continental shelf and the slope. The shelf is broad in the north (about $70 \mathrm{~km}$ in the Gulf of Lions, GoL), narrows to less than $20 \mathrm{~km}$ in the central stretch of the coast (in front of Barcelona city), and then widens again abruptly to about $60 \mathrm{~km}$ further south, in the Ebro Delta Region. The end of the shelf is marked by a fairly steep slope, with a mean value of about 0.01

The focus of this work is placed on the coast off the city of Barcelona, at about $41.3^{\circ} \mathrm{N}, 2.15^{\circ} \mathrm{E}$, in the Northwestern Mediterranean (figure 1). The general circulation in this area has been described in the previous section, and will not be repeated here. The continental shelf is approximately $20 \mathrm{~km}$ wide, in contrast to the much wider shelves to the North (Gulf of Lions) and South (Gulf of Valencia), and plays an important role in determining the local hydrodynamic patterns (Sánchez-Arcilla and Simpson, 2002). Furthermore, storm-related forcings acting at short timescales (Grifoll et al., 2012) and the freshwater input from two rivers (Llobregat and Besòs) can also influence the flow behaviour in the inner-shelf The water flow variability is strongly correlated with local wind pulses which tend to be south-westerly during summer and relatively variable during the rest of the year (Grifoll et al., 2013). The depthaveraged flow at depths shallower than $50 \mathrm{~m}$ tend to be aligned following the isobaths due to the coastal constrain and the importance of the bottom boundary layer. Eventual storms accelerates the along-shelf flow due to the increasing wind stress with a momentum balance dominated by the pressure gradient force (due to sea-level adjustment) that oppose the wind stress (Grifoll et al., 2015). In this case, advective terms may be relevant in the momentum balance during the relaxation period of the storm. The importance of the bottom friction and the proximity of the coastline restrict the development of inertial circulation at the mid and inner-shelf during storms. Stratification mainly occurs in the summer due to positive heat flux, and is broken in autumn and winter by water cooling and wind-induced mixing (Font, 1990; Grifoll et al., 2013). Due to the microtidal character of the Mediterranean Sea, tidal perturbations to the currents are not significant in this area (Poulain et al., 2013; Tsimplis et al., 1995).
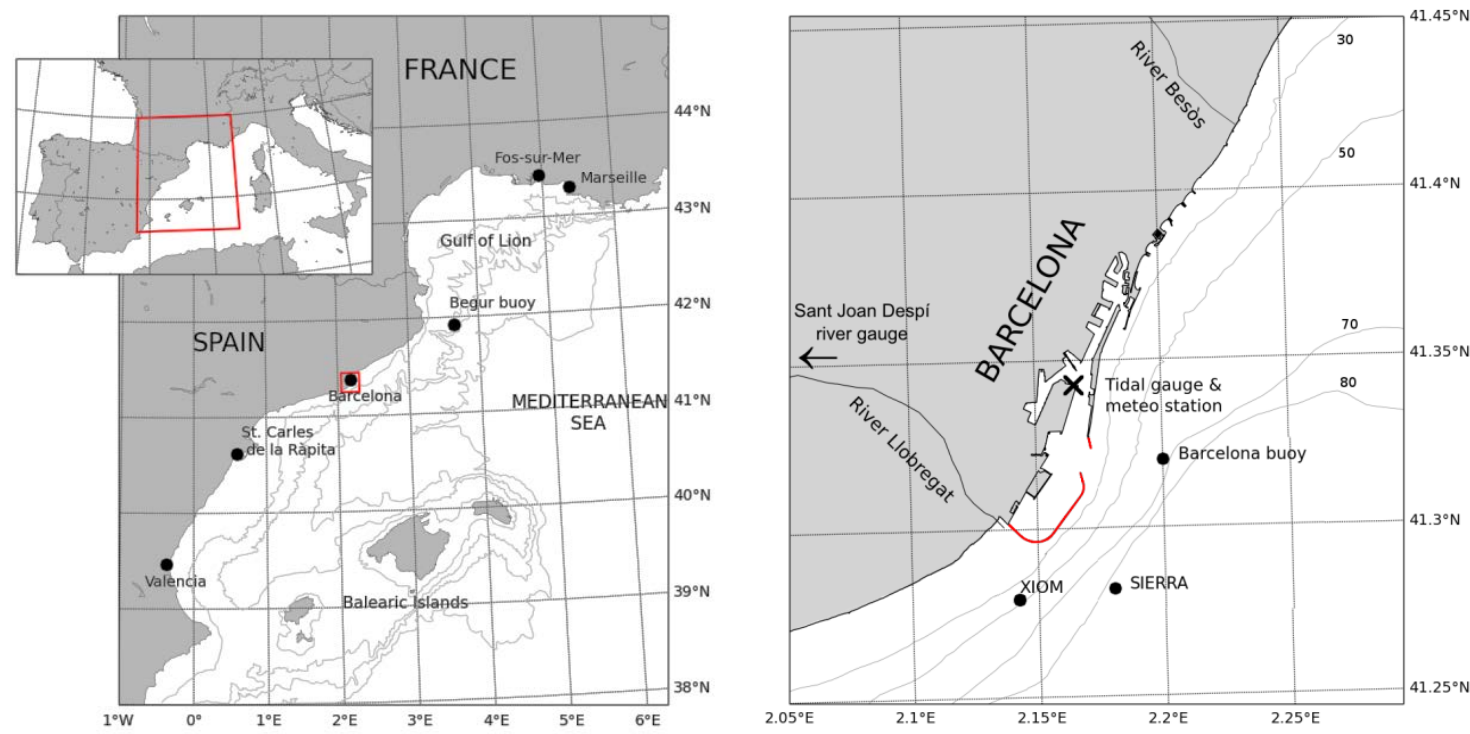

Figure 1: Left) Extended study area, comprising the NW Mediterranean. Focus is placed around the Barcelona area. Other sites from which measured data are used are also shown. Isobaths are drawn at 100, 1000, 1600 and 2400 m. Right) Barcelona harbour, showing the position of the currentmeters, and isobaths up to $80 \mathrm{~m}$. The recent harbour expansion is marked in red. 
The Barcelona coast is highly urbanized, dominated by the presence of a large commercial harbour which has undergone substantial evolution and development during the last decade, particularly with its southward expansion involving the construction of a new seawall and dock (figure 1). The new south configuration of the port has narrowed the coastal shelf locally by about $1.5 \mathrm{~km}$ which, in this particular area, can be up to $20 \%$ of its original width. Coinciding with these changes, the harbour pilots have become aware of the existence of occasional strong current pulses near the south mouth that affect the normal ship approach operations.

\section{3.- METHODOLOGY}

The analysis of currents in the Barcelona harbour vicinity has been based on different datasets from two currentmeters. The currentmeter location and time windows are presented in table 1 and figure 1. The more extensive dataset spans from June 2008 to July 2011 and was recorded by a buoy-mounted Aanderaa DCS 4100 currentmeter deployed approximately $1.9 \mathrm{~km}$ from the Llobregat rivermouth (figure 1). This buoy belongs to the XIOM network (Network of Oceanographic and Meteorological Instrumentation, Bolaños et al., 2009) and provided current data every 10 minutes at $1 \mathrm{~m}$ and $10 \mathrm{~m}$ depths, together with water temperature values. The XIOM time series is complemented with additional measurement sets obtained at a deeper position, at approximately $3.9 \mathrm{~km}$ from the coast (Nortek Aquadopp at SIERRA in figure 1) during the summer of 2008. SIERRA supplied current data every 10 minutes at different depths between $3.2 \mathrm{~m}$ and $12.40 \mathrm{~m}$, with a $0.5 \mathrm{~m}$ vertical resolution.

The XIOM buoy also provided information on the wind and wave fields between June 2008 and July 2011. Supplementary meteorological data was also available from a land-based meteorological station located at La Sirena (figure 1) during June 2008. Daily freshwater flows from the Llobregat river were measured at the Sant Joan Despí gauging station (about $10 \mathrm{~km}$ upstream from the river mouth) and provided by the Catalan Water Agency (ACA). Hourlyaveraged sea level measurements were obtained from the tidal gauge maintained by the Spanish Port Agency (Organismo Público Puertos del Estado) inside the harbour.

\begin{tabular}{|c|c|c|c|c|c|}
\hline Station & Latitude & Longitude & $\begin{array}{c}\text { Mooring } \\
\text { Depth (m) }\end{array}$ & $\begin{array}{c}\text { Measuring } \\
\text { depth }\end{array}$ & $\begin{array}{c}\text { Measuring } \\
\text { period }\end{array}$ \\
\hline XIOM & $41^{\circ} 16.89^{\prime} \mathrm{N}$ & $2^{\circ} 8.18^{\prime} \mathrm{E}$ & 45 & -1 and $10 \mathrm{~m}$. & $\begin{array}{c}\text { 1 Jun } 2008- \\
\text { 26 Jul 2011 } \\
\text { (with gaps) }\end{array}$ \\
\hline SIERRA & $41^{\circ} 16.91^{\prime} \mathrm{N}$ & $2^{\circ} 10.81^{\prime} \mathrm{E}$ & 80 & $\begin{array}{c}\text { between }-3 \\
\text { and }-12 \mathrm{~m}\end{array}$ & $\begin{array}{c}\text { 5 Jun 2008 - } \\
\text { 17 Jul 2008 }\end{array}$ \\
\hline
\end{tabular}

Table 1: Characteristics, position and measuring time window of the currentmeters.

Additional meteo-oceanographic data from other sources and at other locations (see figure 1) have been used to extend the study area in order to identify possible mesoscale causes for the intensifications. Sea level values at Sant Carles de la Ràpita and Valencia have been obtained from a XIOM tidal gauge and the Puertos del Estado observational network, respectively. At both sites, local atmospheric pressure records have been used to find the adjusted sea level (ASL). At Fos-sur-Mer (France), ASL values have been obtained by correcting tidal elevation data from the IOC Sea Level Station Monitoring facility (www.ioc-sealevelmonitoring.org) 
with the atmospheric pressure data given by the www.worldweatheronline.com historical data service at the nearby ( $20 \mathrm{~km})$ Marseille airport, since no local records were found. The reliability of this last source has been positively checked by comparing its atmospheric pressure records in Begur with the values measured at the local Puertos del Estado buoy. Numerical forecasting products obtained from the European Centre for Medium-Range Weather Forecasts (ECMWF, www.ecmwf.int) and the MyOcean project (from May 2015, the Copernicus Marine Environment Monitoring Service, marine.copernicus.eu) have also been used to assess the synoptic scenarios during the intensification events. The former provided 6-hourly data on atmospheric pressure and wind parameters at $10 \mathrm{~m}$, whereas the latter supplied daily-averaged currents, sea levels and water temperature.

As mentioned above, the current data were analysed to identify anomalous intensification events, defined as those in which the water velocities consistently exceed a threshold value during a period of at least 12 hours. Herein, the measurements closest to the surface (i.e., at $-1 \mathrm{~m}$ for XIOM and $-3.2 \mathrm{~m}$ for SIERRA) are used, and the threshold is taken as the monthly $95^{\text {th }}$ percentile. With this criterion, up to 14 distinctive events can be defined during the June 2008 July 2011 period, mostly concentrated in spring (6) and summer (5), with only 3 episodes occurring in autumn (1) and winter (2)). In Espino et al.’s (2011) original study, the threshold magnitude was taken (rather arbitrarily) as $1 \mathrm{~m} / \mathrm{s}$; using this value, only three pulses can be identified in the same period.

In order to simplify the analyses, the five intensification events with a larger difference between the maximum recorded velocity and the monthly median were handpicked (table 2). Because of the different instrumental observation windows and existing data gaps, only one of these events (0806) has been measured simultaneously at more than one currentmeter. The current time series at SIERRA was similar to that measured at XIOM, so the SIERRA dataset will be dropped hereafter, and only the XIOM data shall be used in the analyses.

\begin{tabular}{|l|l|l|c|c|c|}
\hline \multirow{2}{*}{ Event } & \multicolumn{1}{|c|}{ Period } & Station & $\mathbf{u}_{\text {median }}$ & $\mathbf{9 5}^{\text {th }} \mathbf{p c t i l e}$ & $\mathbf{u}_{\text {max }}$ \\
\hline \multirow{2}{*}{0806} & \multirow{2}{*}{ June 2008 } & XIOM & 0.194 & 0.569 & 0.792 \\
\cline { 3 - 6 } & & SIERRA & 0.147 & 0.431 & 0.750 \\
\hline 0812 & Dec. 2008 & XIOM & 0.161 & 0.906 & 1.197 \\
\hline 0904 & April 2009 & XIOM & 0.176 & 0.522 & 0.739 \\
\hline 1003 & Mar. 2010 & XIOM & 0.182 & 0.504 & 1.021 \\
\hline 1010 & Oct. 2010 & XIOM & 0.211 & 0.793 & 1.387 \\
\hline
\end{tabular}

Table 2: Intensification events near Barcelona harbour. All variables are in m/s.

As shown in table 2 and in figure 2, the currents outside the southern harbour mouth occasionally reach values around $0.75 \mathrm{~m} / \mathrm{s}$, with an extreme current speed of $1.39 \mathrm{~m} / \mathrm{s}$ recorded during the October 2010 event. During the full measuring period (June 2008 to July 2011) the mean, median and standard deviation of the surfacemost current were $0.200,0.155$ and 0.157 $\mathrm{m} / \mathrm{s}$, respectively, whereas at $10 \mathrm{~m}$ depth these values were $0.200,0.170$ and $0.146 \mathrm{~m} / \mathrm{s}$; these values, together with the correlation coefficient between both timeseries $(0.75)$ indicate the presence of a general barotropic flow in this area. Although the periods of enhanced flow speed are relatively short, lasting approximately between 19 and 57 hours, they increase the typical local current magnitude by a 4-7 factor, sufficient to disrupt normal harbour access for a period of 2-4 days. 


\section{4.- RESULTS}

The flow magnitude and direction as measured by the XIOM currentmeter at $1 \mathrm{~m}$ and $10 \mathrm{~m}$ depth are presented in figures 2 and 3 for the five events from table 2. The duration of each event (i.e., the time during which the velocity consistently exceeded the $95 \%$ threshold) is identified by the shaded box. Also depicted in the figures is the daily mean Llobregat river flow at the Sant Joan Despí gauging station, normalized to fit the plot axes; the maximum flow value is also provided. Water temperature values (not shown) were very uniform with depth, with differences no larger than $0.5^{\circ} \mathrm{C}$ between both levels. However, and broadly coinciding with the 1010 intensification occurrence, a $4^{\circ} \mathrm{C}$ drop in relation to the previous days was observed at a nearby Puertos del Estado wave buoy (figure 1). This decrease in water temperature will be further analysed in section 5.2.

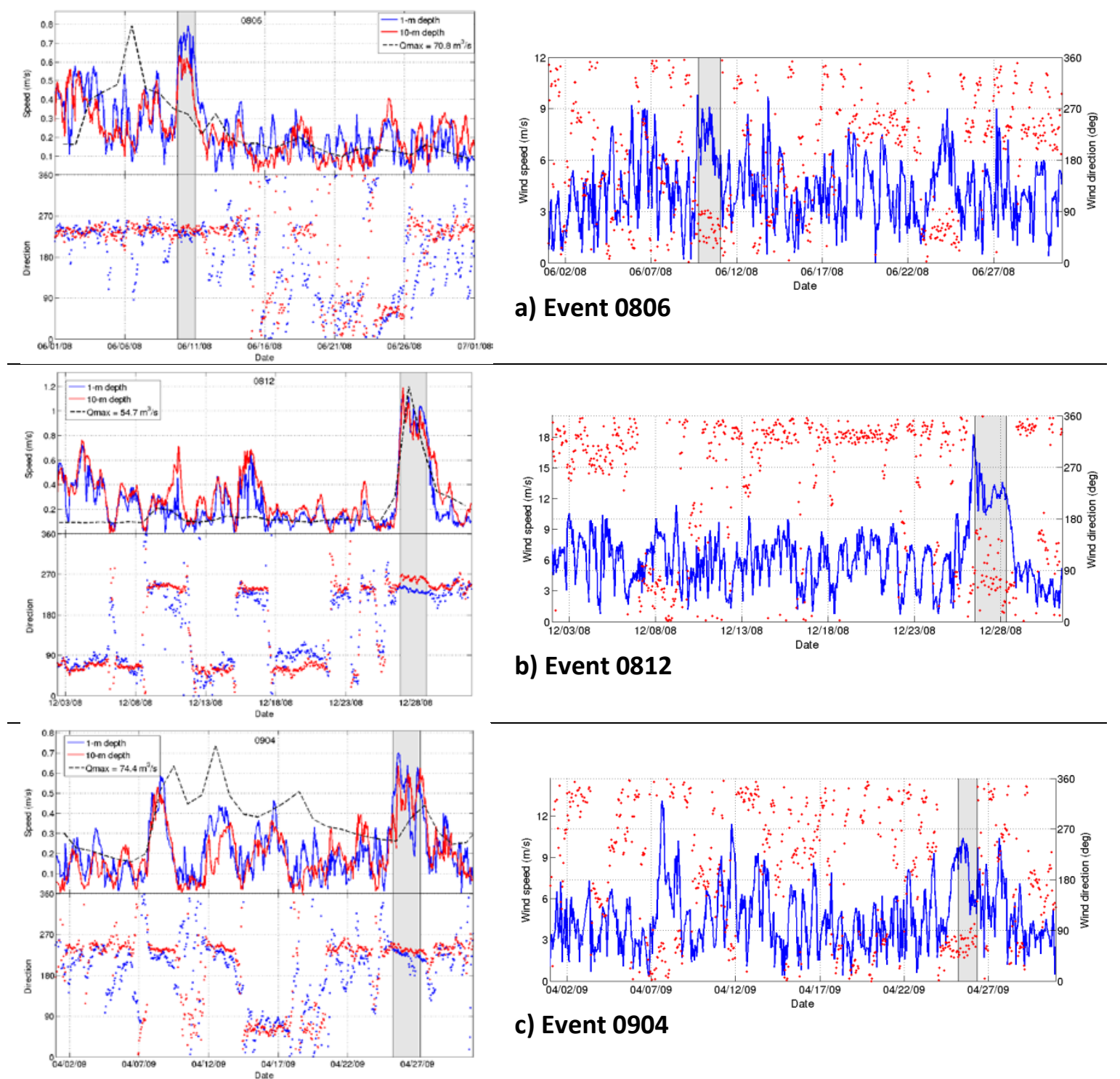

Figure 2: Left) Current speed and direction recorded by the XIOM buoy at 1-m depth (blue) and 10-m depth (red) during events 0806, 0812 and 0904. The dashed line shows the normalized daily mean Llobregat river flow; maximum river flows are specified in the legend box. Right) Wind speed (blue) and direction (red) recorded at the XIOM buoy during events 0806, 0812 and 0904. In each case, the event is identified by the shaded area. Note that the scale of the y-axis differ between events. 
Also shown in these figures (right column) are the wind speed and direction (following the usual oceanographic convention) recorded at the XIOM buoy for all the events. During March 2010 (event 1003), wind data was not measured during the first half of this month, coinciding with the current enhancement phase, and the available time series has been complemented with the ECMWF predictions at the numerical node closest to the XIOM buoy (1.18 km).
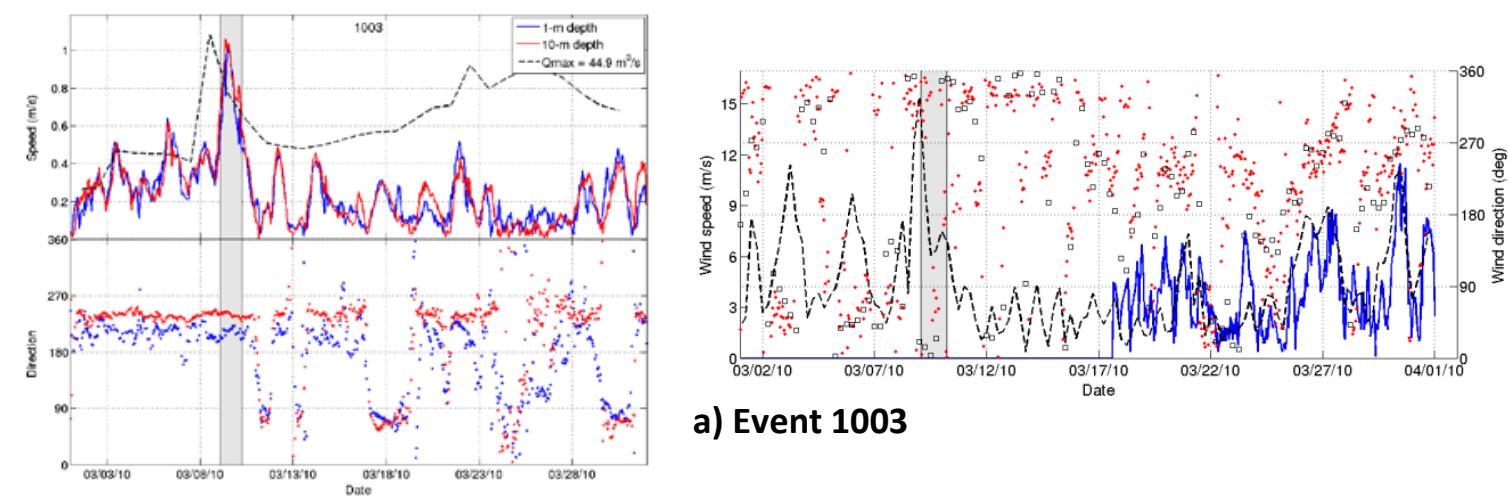

a) Event 1003
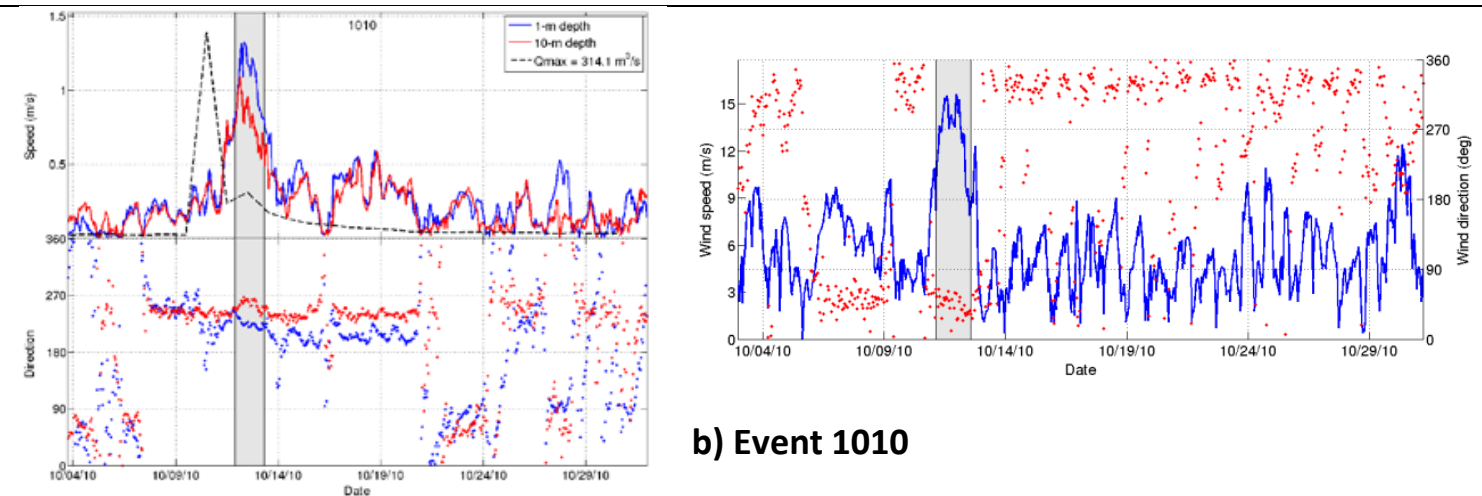

b) Event 1010

Figure 3: As for figure 2, but for events 1003 and 1010. In the top right panel, the dashed line and squares correspond to wind speed and direction as given by the ECMWF at the grid node nearest to the XIOM buoy (see text for explanation).

The first event started on June 9th, 2008, and lasted for about 19 hours (figure 2a), during which the flow speed increased from $0.17 \mathrm{~m} / \mathrm{s}$ to $0.75 \mathrm{~m} / \mathrm{s}$. Three days before the event, on June $6^{\text {th }}$, a $70.8 \mathrm{~m}^{3} / \mathrm{s}$ peak of freshwater discharge was measured at the gauging station, decreasing slowly to typical $15 \mathrm{~m}^{3} / \mathrm{s}$ values. During this period, prevailing winds from NE-E, with maximum speeds of around $9 \mathrm{~m} / \mathrm{s}$ were observed in this area.

The second event (figure 2b) began on December $26^{\text {th }}$, 2008, and extended over the following 57 hours. During the first 11 hours, the current speed increased from $0.17 \mathrm{~m} / \mathrm{s}$ to $1.16 \mathrm{~m} / \mathrm{s}$, and remained intermittently above $1 \mathrm{~m} / \mathrm{s}$ for 36 hours. A peak mean freshwater discharge of 54.7 $\mathrm{m}^{3} / \mathrm{s}$ was recorded on December $27^{\text {th }}$, coinciding with the flow intensification. Prevailing winds during these days exceeded $10 \mathrm{~m} / \mathrm{s}$, with a maximum wind speed of $18.3 \mathrm{~m} / \mathrm{s}$, blowing mostly from the NE to SE

The 0904 episode (figure 2c) lasted for 47 hours, starting on April $25^{\text {th }}, 2009$, and showed a 60 $\mathrm{cm} / \mathrm{s}$ increase of the current speed in the first 19 hours, reaching a maximum of $0.74 \mathrm{~m} / \mathrm{s}$. There was a freshwater outflow peak of $44.2 \mathrm{~m}^{3} / \mathrm{s}$ coincident with the end of the flow pulse but, in contrast with the other events, the river discharge was relatively important before the 
intensification, with a $41.6 \mathrm{~m}^{3} / \mathrm{s}$ mean during the previous two weeks. Maximum wind speeds over this period were of about $10 \mathrm{~m} / \mathrm{s}$, mainly due to northeasterlies.

The fourth event (1003, figure 3a) started on March $9^{\text {th }}$ and extended over a 31 hour period, including an initial increase in flow velocity from $0.28 \mathrm{~m} / \mathrm{s}$ to just over $1 \mathrm{~m} / \mathrm{s}$. The maximum Llobregat outflow $\left(44.9 \mathrm{~m}^{3} / \mathrm{s}\right)$ preceded the intensification event by one day, and the freshwater discharge remained between 25 and $35 \mathrm{~m}^{3} / \mathrm{s}$ during the episode. As mentioned above, no wind data was available for this event.

Finally, the 1010 intensification event (figure 3b) started on October $11^{\text {th }}, 2010$, and finished 35 hours later, with an increase in current speed from $0.19 \mathrm{~m} / \mathrm{s}$ to $1.39 \mathrm{~m} / \mathrm{s}$. A very high peak of freshwater discharge $\left(314 \mathrm{~m}^{3} / \mathrm{s}\right)$ was measured one day before (Oct $\left.10^{\text {th }}\right)$, and a secondary 70.6 $\mathrm{m}^{3} / \mathrm{s}$ peak was also measured during the event. Strong winds of up to $15 \mathrm{~m} / \mathrm{s}$ blowing from the NE prevailed over this period.

The first visual analyses of the data reveal some features that are common to all the considered events. The intensifications were observed at both the surface and the deeper positions, with a similar current evolution at $1 \mathrm{~m}$ and at $10 \mathrm{~m}$ depths in terms of magnitude and duration. During the events, the correlations coefficients between surface and deeper currents were 0.26 for event 0904, 0.64 for 1010, and larger than 0.85 for the rest. The current at both depths was generally southwestward, following the local isobaths and in consonance with the direction of the local winds.

The complex correlation coefficient (Kundu, 1976) shows that there is a connection between the currents and the local wind, as pointed out by Espino et al. (2011), with an amplitude that increases significantly during the intensification times and wind intensity peaks coinciding with the current pulses. For instance, the correlation coefficient for wind and current speeds during June 2008 and October 2010 is 0.15 and 0.51 , respectively, but increases to 0.73 and 0.86 during the strong current episodes. This correlation increase can be illustrated with the accumulated correlation coefficient (i.e., the value at time $t$ representing the correlation between current and wind data from the first instant $t_{0}$ to $t$ ) for each event (figure 4 , left), which shows a sharp increase during the intensification period. The exception is event 0904, but in this case the accumulated correlation is already high due to a previous weaker flow intensification observed around April $7^{\text {th }}$. The phase angle of the complex correlation coefficient (figure 4, right), which measures the average angle between the current and the wind, varies during the events. For all the intensifications except 0812 the average veering of the currents in relation to the wind at the onset of the pulse is between $15^{\circ}-28^{\circ}$ to the right (clockwise), consistent with Ekman's theory in shallow waters, but it reduces to values close to zero by the end of the event, strengthening the causal relationship between the wind stress and the currents. On the contrary, for the December, 2008 event, the average veering of the currents in relation to the wind was about $30^{\circ}$ to the left (counterclockwise); however, this episode had the strongest winds from the East (up to $18 \mathrm{~m} / \mathrm{s}$ ), and this cyclonic veering reflects the steering effect of the coastal boundary on the waterflow, leading to a potential downwelling signal that could not be verified due to the lack of water temperature and salinity measurements. 

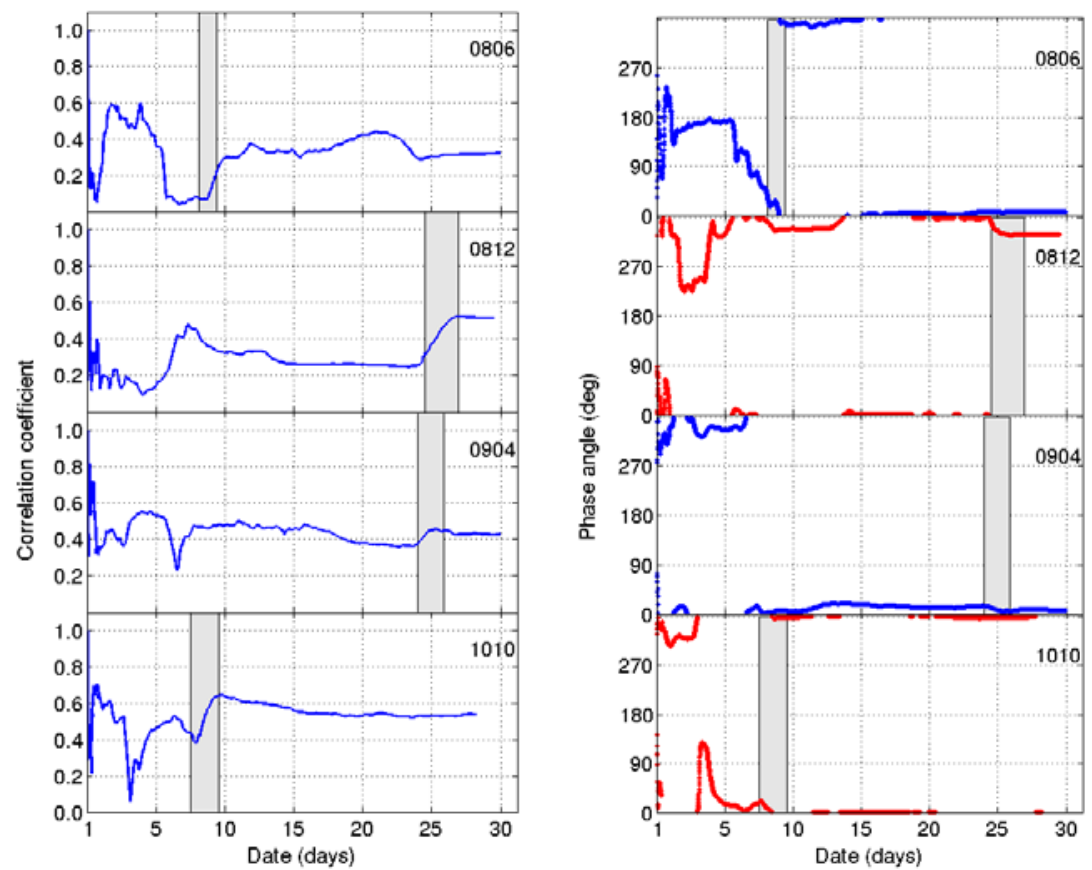

Figure 4: Correlation coefficient between surface current and wind speed as a function of time, for events 0806, 0812, 0904 and 1010.

On the other hand, peaks in the freshwater discharge from the Llobregat River were observed previously or during to the flow intensifications. In the first case, the presence of the freshwater plume, combined with the local wind forcing, generally introduced a small baroclinic component into the flow, enhancing the surface currents as compared to deeper flows. This is clear, for example, in cases 0806 and 1010 (figures 2a and 3b). Stronger intensifications coincide with concurrent discharge peaks. The existence of a lighter layer of water in the area during the flow pulses might also explain why other similar wind episodes (e.g., around June 25 , in figure $2 b$ ) did not result in equivalent current increases.

\section{5.- DISCUSSION}

The direct analysis of the in-situ data indicates that current intensifications in this stretch of coast are mainly induced by locally strong and persistent winds blowing from the NE to SE, as suggested by the close correlation between both variables. Other mechanisms, like topographic constraints and local transient phenomena, such as the narrowing of the continental shelf in front of the Barcelona coast and the freshwater discharge from the Llobregat River respectively, might play a secondary role by contributing to enhance the flow acceleration due to the wind.

The former issue was shown by Grifoll et al. (2013), who used the 1010 episode to validate their application of the ROMS numerical model ROMS (Shchepetkin and McWilliams, 2005) for the analysis of the seasonal circulation over the Catalan inner-shelf north of Barcelona between May 2010 and April 2011. By driving their high-resolution system with MyOcean daily output at the open boundaries, daily ECMWF atmospheric forcing and daily-averaged Llobregat freshwater discharge (see details in their paper), and comparing the output with the XIOM buoy data and three ADCPs mounted north of Barcelona, they managed to reproduce the flow 
intensification to an acceptable degree. The sequence of modelled adjusted sea level and dailymean current is shown in figure 5.

The numerical ASL captures well the observed evolution of the adjusted sea level close to the tidal gauge position, taking into account the daily character of the model forcings, and the spatial resolution of their grid. The water circulation pattern evidences a clear spatial variability in the area, where strong currents are originated in front of Barcelona harbour coinciding with the narrowing of the shelf due to the presence of the harbour. With their numerical model, Grifoll et al. (2013) managed to reproduce the flow intensification (see their paper for a graphical and statistical comparison) and also the aforementioned drop in seawater temperature (not shown).

Since they were using a daily-averaged river outflow, it is difficult to assess the exact effect of the riverine outflow on the coastal currents, but the agreement they found suggests that the role of the freshwater on the event recorded in October, 2010 is of secondary importance as compared to other forcings such as the wind. For the 0806 event, the position of both the XIOM and SIERRA buoys in relation to the river mouth make it very plausible that they are inside the bulge of the freshwater plume when the N-NW winds settle in. For this episode, the outflow peak occurred 3 days before the intensification, but for the previous 2 days the freshwater discharge was higher than about $35 \mathrm{~m}^{3} / \mathrm{s}$, and coincided largely with winds from the W-N, contributing to extend the plume offshore. In other cases with similar wind characteristics, the absence of a surface layer of fresher water might reduce the intensity of the flow pulses.
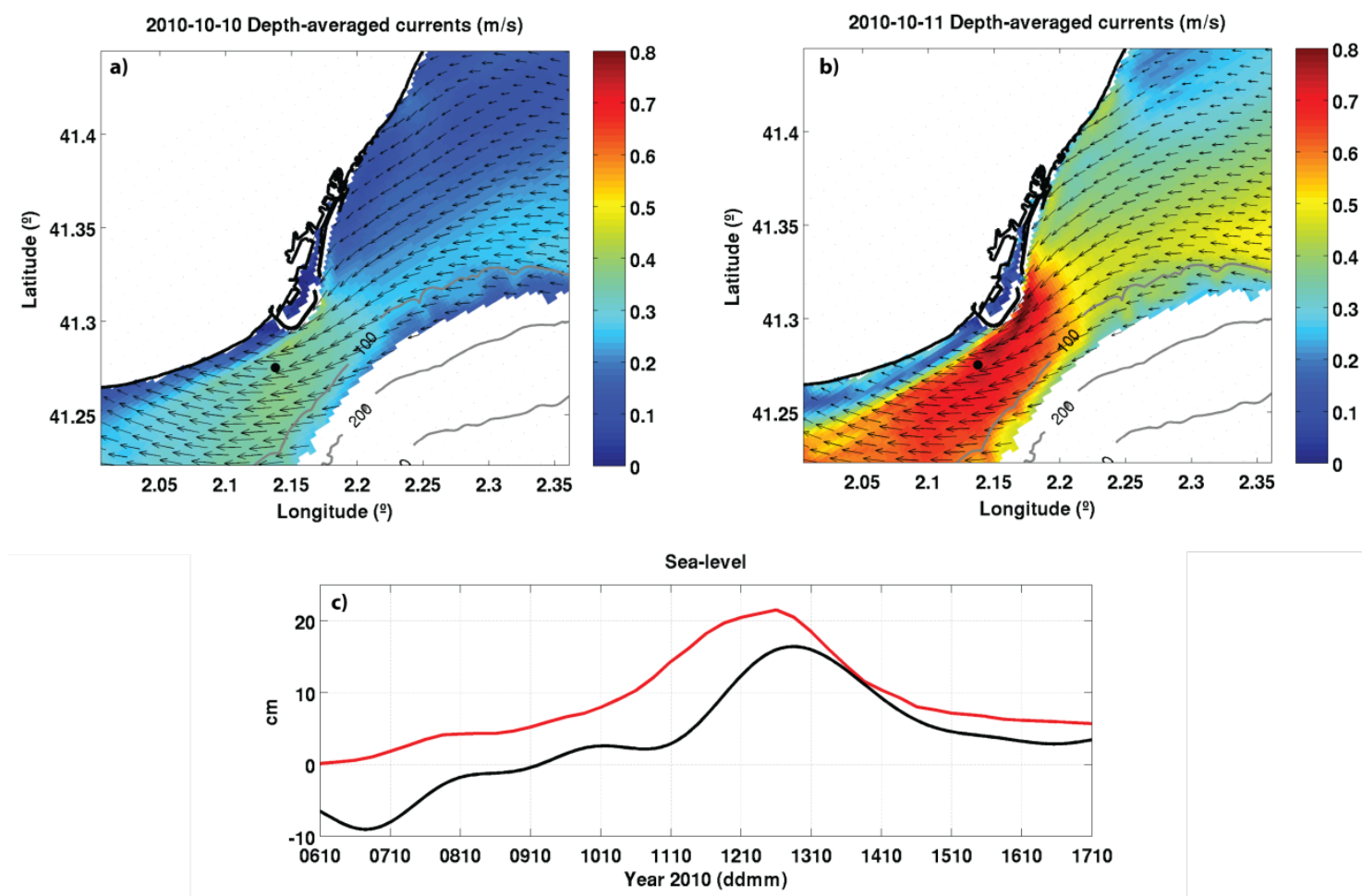

Figure 5: (a, b) Daily mean depth-averaged modelled circulation up to the $150 \mathrm{~m}$ isobaths during the 1010 event. c) Observed (black) and modelled (red) ASL during the same event.

From this basis, it is worthwhile to derive a simple description of the regional atmospheric patterns that lead to these intensification events. Supported by actual meteorological forecasting, such a description would allow predicting the likely occurrence of flow accelerations, thus 
permitting to take them into consideration when planning harbour operations or other coastal activities. Based on the outcome of this analysis, further attention is dedicated to event 1010 . This is described in the following sections.

\section{1.- Synoptic scale analysis}

An analysis of the regional atmospheric and oceanographic conditions in the days leading to the events has been done using the 6-hourly forecasts provided by the ECMWF at a $0.125^{\circ} \mathrm{x} 0.125^{\circ}$ resolution, and the MyOcean daily forecasts at a resolution of $0.0625^{\circ} \mathrm{x} 0.0625^{\circ}$.

The respective atmospheric scenarios present some commonalities for all the events. They all coincide with strong and persistent winds blowing from the NE to SE over the NW Mediterranean, with velocities that occasionally reach between $16-20 \mathrm{~m} / \mathrm{s}$. These atmospheric flows are induced by the coexistence of a low-pressure centre located over the Iberian Peninsula and a high-pressure area over Central Europe. This pattern is illustrated in figures 6 and 7, which show the mean sea level pressure and wind speed and direction corresponding to events 0904, 1003 and 1010. In figure 6a, a depression develops over the eastern half of Iberia in the hours leading to the 0904 episode, whereas the high located initially over Slovenia shifts northeastwards. The resulting pressure distribution facilitates the apparition in the NW Mediterranean of winds with a significant easterly component (figure 6b). Similar synoptic scenarios are apparent in figure 7 for events 1003 (a) and 1010 (b). For both 2010 intensifications, the Iberian low-pressure centre moves slowly along the coast. For 1003 (figure 7a), this depression enters the Mediterranean Sea just south of Valencia, travels northward and remains stationary north of the Balearic Islands; for 1010 (figure 7b), the low enters the coast south of the GoL and then moves southward, being replaced by another depression coming from North Africa that remains for 12 hours over the Balearic Islands. The trajectory of these lows is indicated in figure 7.

However, divergences in the atmospheric situation leading to the various events are also apparent. Whereas in the first four cases (except 1010), the onset of intense (south- or north-) easterlies follows a prolonged period of up to two weeks of strong $\mathrm{N}$ (Tramontane) and NW (Mistral) winds blowing into the Gulf of Lions, event 1010 is preceded by a sustained period of strong E (Levante) winds blowing over the GoL and along the Catalan coast. This difference can be seen by plotting the stickplot of the ECMWF wind for events 0904 and 1010, as modelled close to the centre of the GoL (3.75E, 42.75N) (figure 8). 


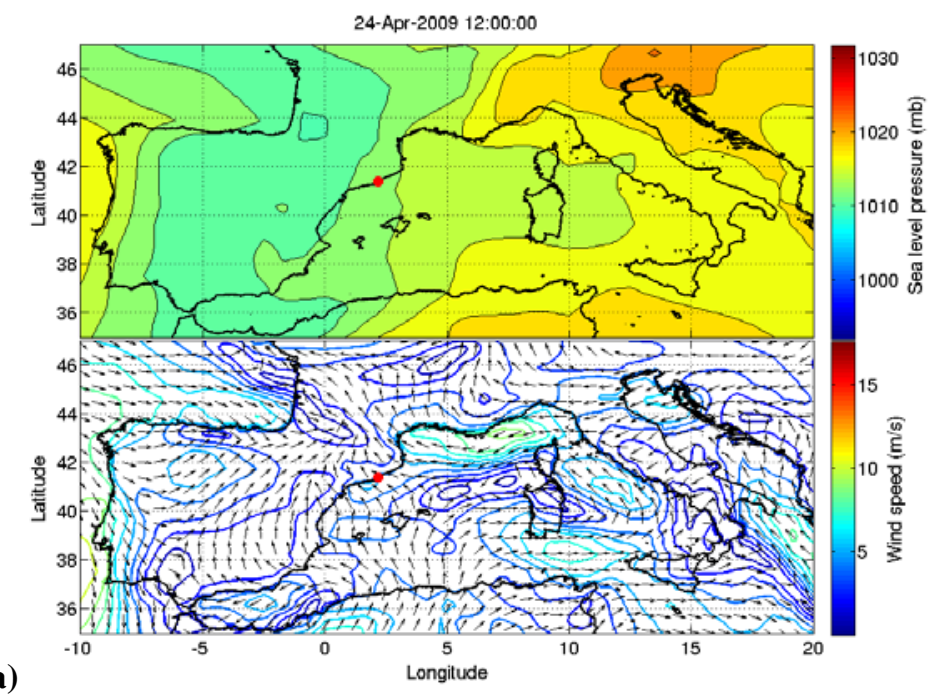

a)

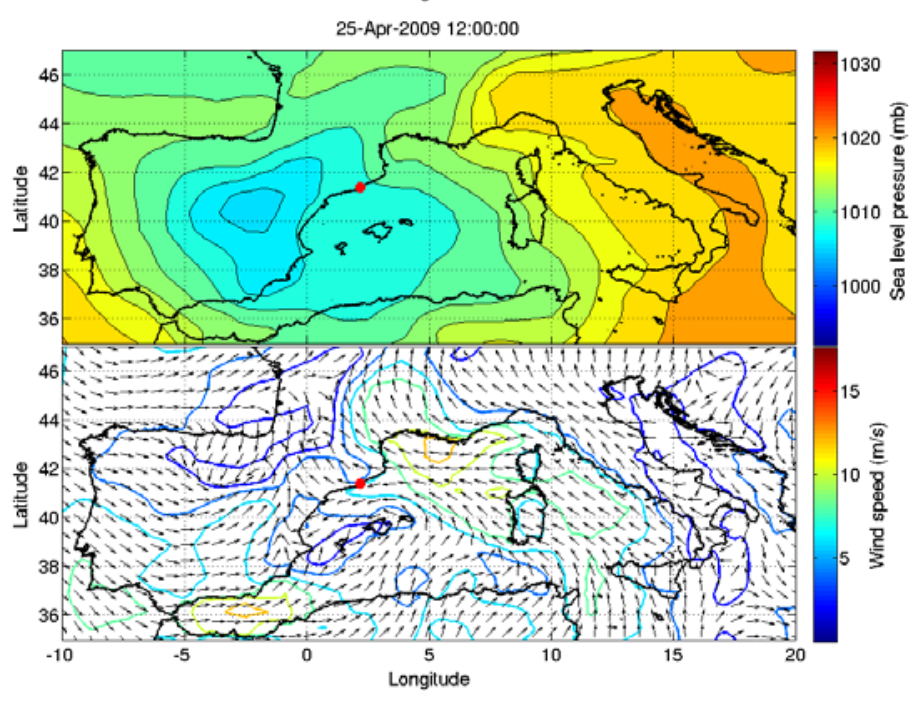

b)

Figure 6: Mean sea level pressure and wind at $10 \mathrm{~m}$ at two times during April, 2009 (event 0904).

a)

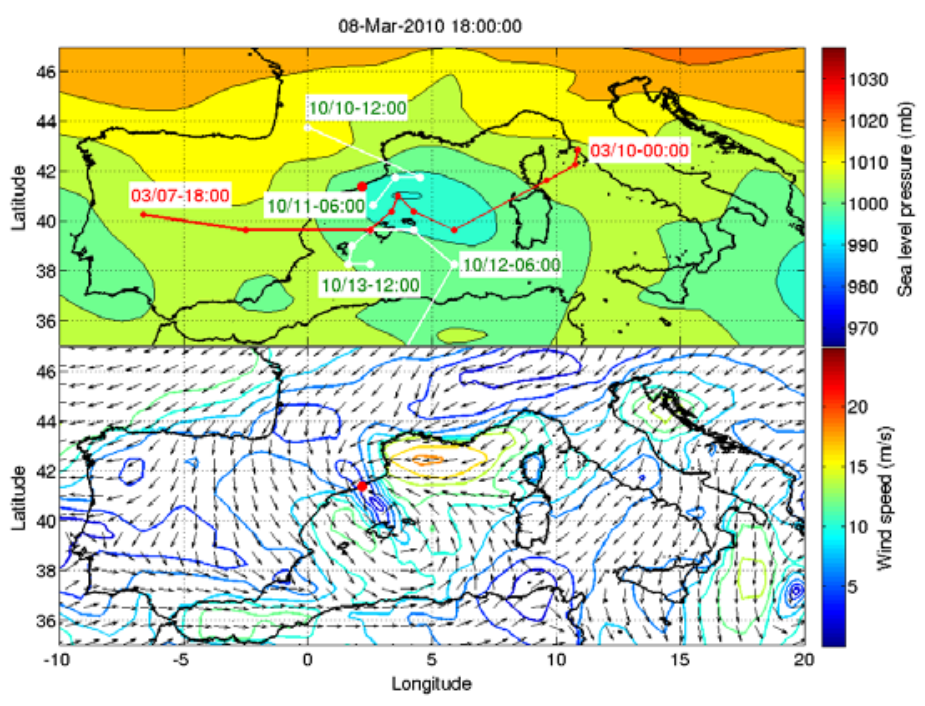




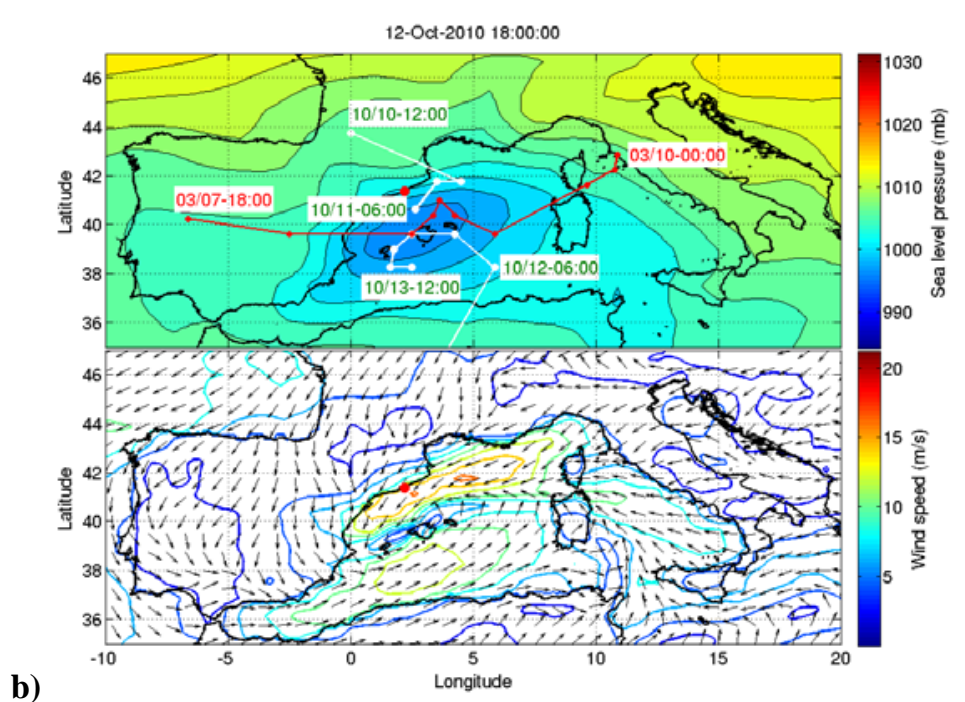

Figure 7: Mean sea level pressure and wind at $10 \mathrm{~m}$ during the March, 2010 and October, 2010 (events 1003 and 1010). Also shown are the trajectories of the low-pressure centres in March, 2010 (red), and October (white).
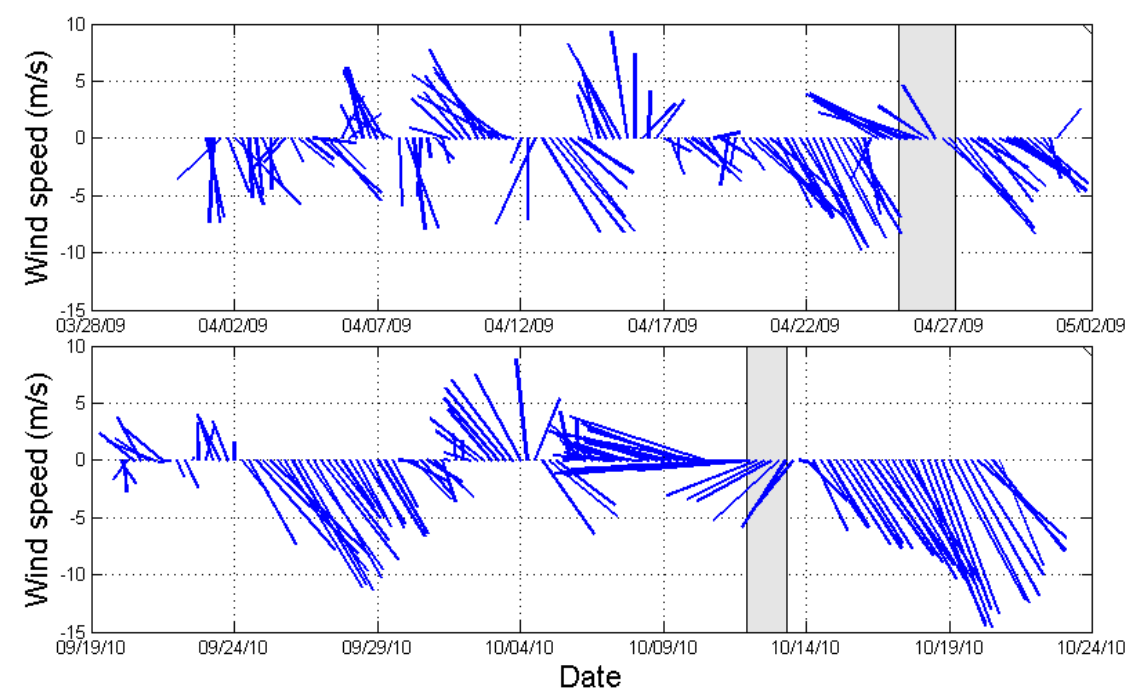

Figure 8: Stickplots of ECMWF wind in the Gulf of Lions during April 2009 (top) and September-October 2010 (bottom). The shaded boxes correspond to the intensification events 0904 and 1010.

The aforementioned differences in atmospheric conditions between the first four events and event 1010 are replicated in the daily mean hydrodynamic patterns provided by the MyOcean forecasting system. For events 0806, 0812, 0904 and 1003, associated to a previous history of strong N-NW winds, the surface current pattern in the NW Mediterranean is characterized by the presence of numerous eddies and filaments, together with a quasi-permanent southward current on the shelf break. Figure 9 shows the current and sea level anomalies relative to the monthly mean value for event 0904 . The daily mean sea level anomaly for these events shows a (synchronic) increase at the coast of about $5 \mathrm{~cm}$, much weaker than the observed signal, but compatible with the observations at the Barcelona tidal gauge. This variation in sea level values is also similar to the mean wind-induced setup expected for these winds according to the simple 1D model proposed by Kamphuis (2000) to estimate storm surge: 


$$
\frac{d S}{d x}=\frac{\xi(u \cos \phi)^{2}}{g D}
$$

where $\mathrm{S}$ is the storm surge, $x$ is the distance over which the storm surge is calculated, $u$ is the wind speed, $\phi$ is the angle between the wind direction and the $x$-axis, $D$ is the new depth of the water $(d+S)$, and $\xi\left(=3.2 \cdot 10^{-6}\right)$ is a constant. Here, using a mean bottom profile of the Catalan coast and average wind parameters during the events yields a storm surge between 4 to $9 \mathrm{~cm}$ high. Therefore, we conclude that this increase in sea level is due to local wind setup.

For the 1010 case, preceded by persistent easterlies in the GoL, the shelf break current is replaced by a meandering current located farther offshore, and by a narrow coastal current that originates in the GoL and is also observed later on along the Catalan coast (figure 10). The maximum daily mean flow speeds within this jet (approximately $1 \mathrm{~m} / \mathrm{s}$ ) are found off Barcelona on October, $12^{\text {th }}$, probably linked to the narrowing of the continental shelf in this area. The daily mean sea level also increases (between 6 and $20 \mathrm{~cm}$, depending on the latitude) and shows the same "southward-propagating" behaviour as for the currents. The magnitude, timing and evolution of both the currents and the sea level are consistent with values observed in Barcelona; furthermore, the modelled water temperature shows a $4^{\circ} \mathrm{C}$ decrease during the intensification, which is also captured by a Puertos del Estado buoy located offshore from Barcelona.
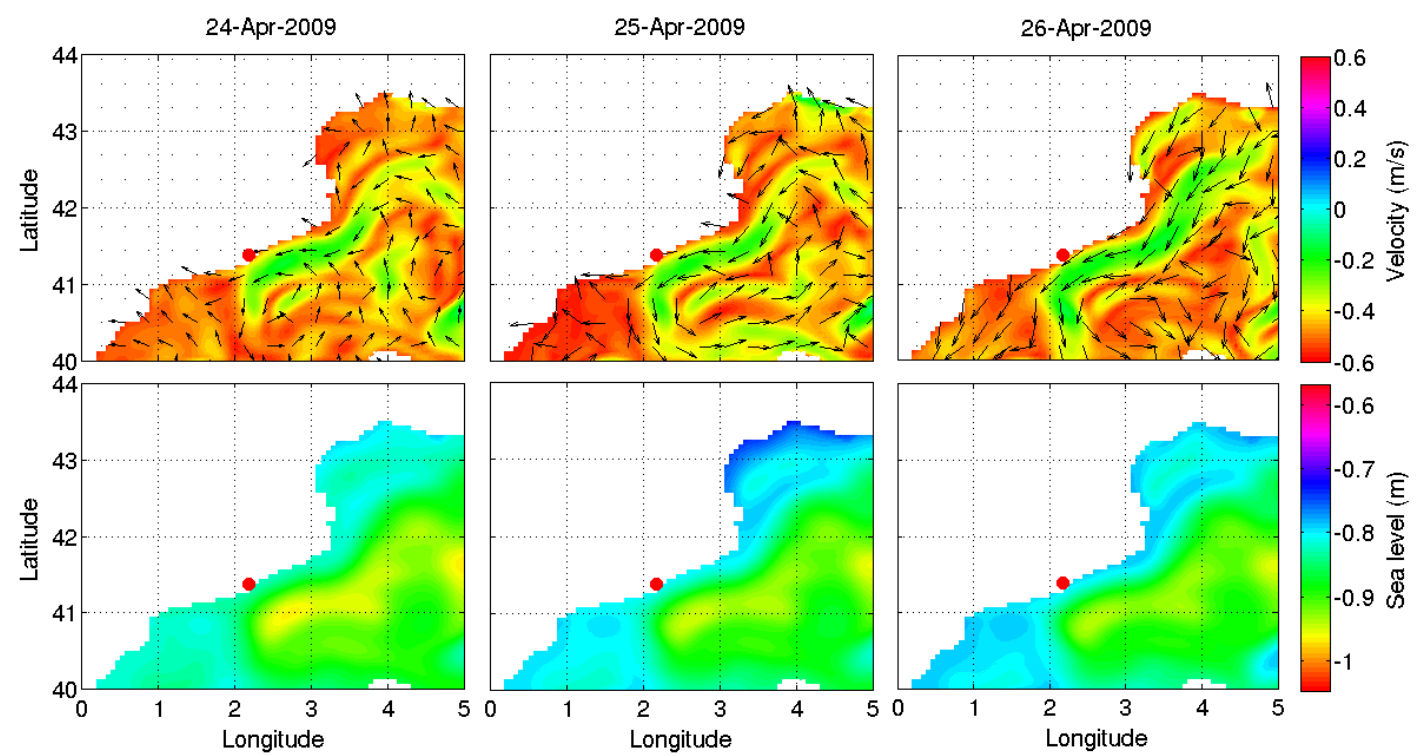

Figure 9: Daily mean surface current (top) and sea level (bottom) anomalies during April, 2009 (event 0904), from the MyOcean-MEDSEA operational forecasting system. 

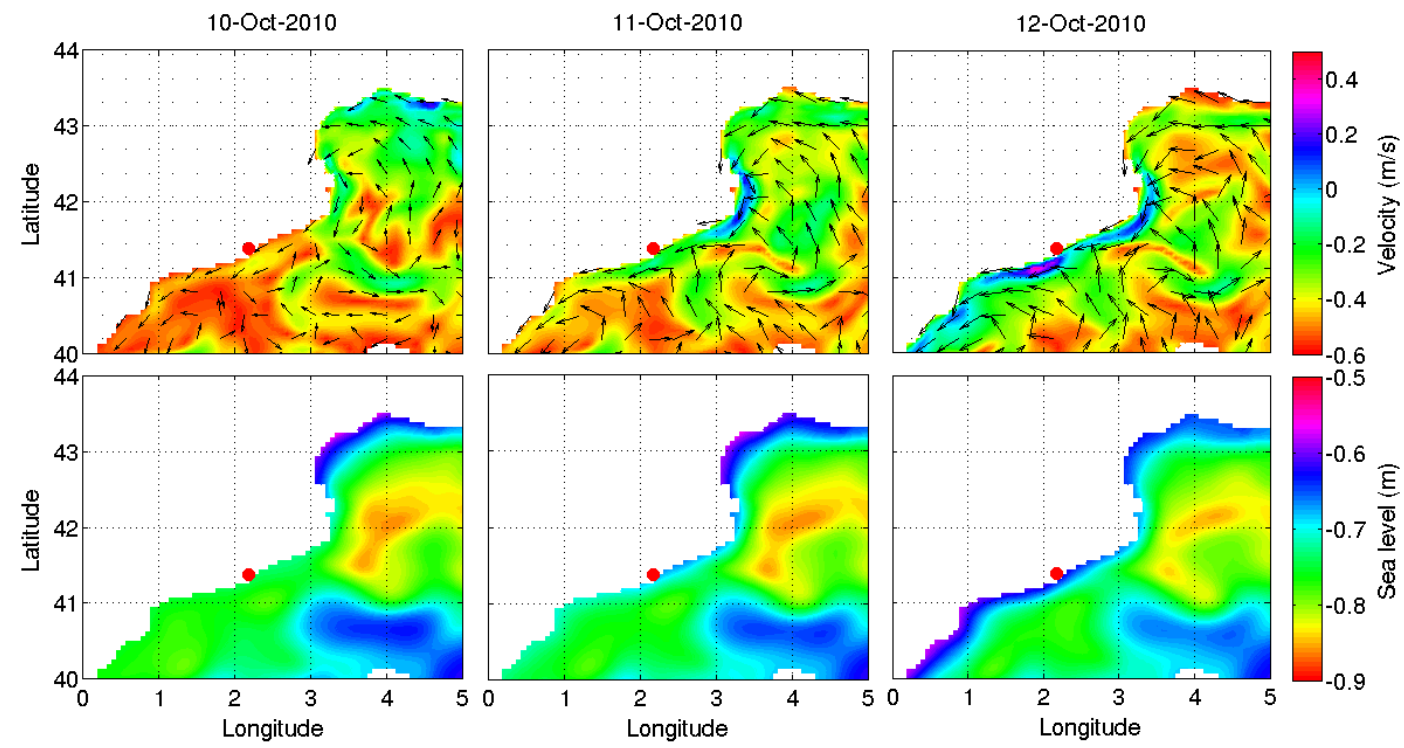

Figure 10: Daily mean surface current (top) and sea level (bottom) anomalies during October, 2010 (event 1010).

\section{2.- Event scale analysis: the October, 2010 intensification}

The singular characteristics of the 1010 episode suggests that other factors, in addition to local wind forcing combined with shelf narrowing, might be playing a role in the coastal flow intensification. In particular, the MyOcean results show a perturbation apparently propagating southward from the Gulf of Lions, resulting in stronger flows, higher sea levels, and lower water temperatures off the Barcelona coast. These are compatible with the aforementioned drop in seawater temperature observed at the offshore Puertos del Estado buoy, and with the $36 \mathrm{~cm}$ rise of the sea level during a three-day period measured at the Barcelona harbour tidal gauge (see figure 5,c). To analyse this phenomenon, the adjusted sea level (ASL) at Barcelona and three additional tidal measuring stations along the NW Mediterranean coast (Fos-sur-Mer, Sant Carles de la Ràpita and Valencia; figure 1) have been obtained by removing the effects of the local atmospheric pressure (inverse barometer correction) on the detided and detrended sea level, and filtering out the variance below the 2 day band to eliminate higher-frequency signals. All the monitored stations show disturbances during the same period that are analogous to that observed at Barcelona (figure 11, left), and the time lagging of ASL peaks at the four stations suggests the presence of a transient perturbation in the coastal trapped wave (CTW) category propagating southward along the shelf. Further evidence of the presence of a CTW during this event can be obtained by correlating the alongshore component of the flow $(v)$ with the crossshore gradient of the adjusted sea level $(\Delta \eta / \Delta x)$. For long CTW, both variables should be in geostrophic equilibrium (LeBlond and Mysak, 1978), implying a linear relationship between alongshore current changes and variations of the sea level at the coast:

$$
f v=g \frac{\Delta \eta}{\Delta x}
$$

where $f$ is the Coriolis frequency, $g$ is gravity's acceleration, and $\Delta x$ is a cross-shore lengthscale. Due to the lack of sea level measurements along a cross-shelf section, Schumann and Brink (1990) correlated longshore currents with sea level data in South Africa and found linear regression coefficients that were high enough "for some confidence to be placed in the 
geostrophic relation”. Following their approach, the relation between $v$ and $\eta$ during October 2010 as measured in Barcelona has been obtained (figure 11, right). In this plot, blue circles and red squares correspond to data acquired during the 1010 event (before and after the ASL peak, respectively). During the complete event, there is a significant relation between the adjusted sea level and the alongshore velocity, with a correlation coefficient of 0.72 . The correlation is somewhat higher during the first half of the event $\left(10^{\text {th }}-12^{\text {th }}\right.$ Oct, $\left.R=0.96\right)$ corresponding to the increasing sea levels, than during the last half $\left(12^{\text {th }}-14^{\text {th }}\right.$ Oct, $\left.R=0.85\right)$. A linear regression for both subsets of data yields large determination coefficients (0.92 and 0.73), as shown in figure 11, right (blue and red solid lines), suggesting a quasi-geostrophic behaviour of the hydrodynamics during the event.
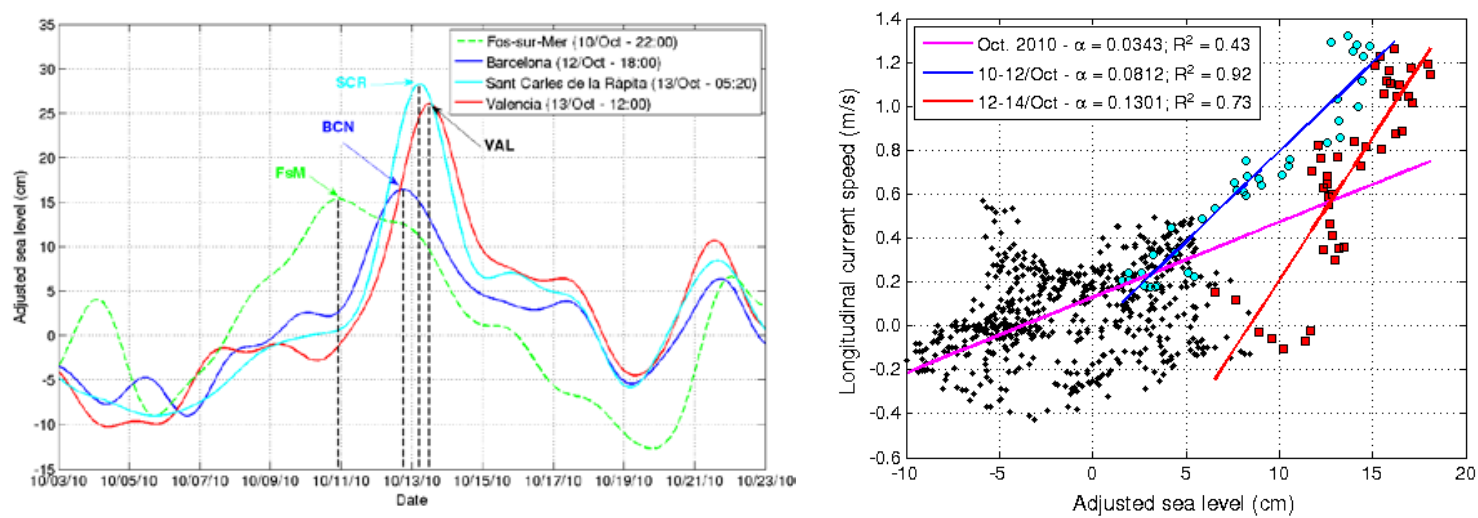

Figure 11: Left) Filtered adjusted sea level (ASL) at four measuring stations along the NW Mediterranean coast for October 2010. Right) Alongshore current vs. adjusted sea level in Barcelona during October 2010. Blue circles and red squares correspond to the acceleration and deceleration phase of the 1010 event, respectively. Also shown are the corresponding linear regression functions. Positive currents are southwestwards.

Deviations observed from the theoretical geostrophic behaviour could be related to frictional terms, wave-induced momentum flows and baroclinic forcing. Although Grifoll et al. (2013) showed that the former two (i.e., friction and wave-forced flows) are small compared to the Coriolis and cross-shore sea level gradient terms in the Barcelona inner shelf at long (monthly) timescales, they can become important at smaller (event) scales, especially during more energetic periods. On the other hand, the baroclinic component of the pressure gradient can also be relevant, taking into account the continuous freshwater discharge during the days previous to the event and, in particular, the $314 \mathrm{~m}^{3} / \mathrm{s}$ (daily mean) outflow from the Llobregat river on $10^{\text {th }}$ October. Some of these factors might also explain the asymmetry obtained in the slope of the linear regression between the acceleration and deceleration phases of the pulse, but it is difficult to draw conclusions from one single event and using such a short timeseries.

The existence of such waves in this area was determined by Jordi et al. (2005) after studying velocity and sea level records at different locations in the north Catalan Sea. Their correlations indicated the presence of southward propagating waves at phase speeds of 9.20, 2.30, 0.90 and $0.40 \mathrm{~m} / \mathrm{s}$, the last three of which were close to the values predicted by Brink and Chapman's (1985) model for free CTW modes (2.43, 0.85 and $0.40 \mathrm{~m} / \mathrm{s}$ ) in the area. Taking into account the approximate distance along the coast between Fos-sur-Mer and Barcelona (440 km, which includes Jordi et al.'s (2005) study area) and the time lag between corresponding peaks, the observed ASL signal could be associated to a CTW with a phase speed of $2.78 \mathrm{~m} / \mathrm{s}$, consistent with the first free CTW mode given in Jordi et al.'s (2005) work. According to Brink (1982), this first mode is the main responsible for determining the dynamics of the coastal pressure 
field. South of Barcelona, the widening of the continental shelf contributed to speeding up the CTW (Battisti and Hickey, 1984), which travelled at a mean phase speed of about $5.00 \mathrm{~m} / \mathrm{s}$ along the eastern Spanish coast, considering the distance and time delay between Barcelona and Valencia. The relationship between wind-forced coastally-trapped waves and coastal sea level, temperature and flow fluctuations has been described by numerous studies in different coastal systems (e.g., Brink, 1982; Schuman and Brink, 1990; or Jordi et al., 2005, amongst others). Although it is widely accepted that the main forcing for CTW is the alongshore component of the wind (Schumann, 1983), the complex bathymetry of the NW Mediterranean continental margin and the interaction of Kelvin waves associated to the Northern Current with the east edge of the GoL shelf (Echevin et al., 2003) can alter the simple wind-forced generation theory (Jordi et al., 2006).

A plausible alternative to justify the sequence of sea level peaks along the coast would be the simple piling of water by the onshore component of a wind jet moving southward. This explanation, however, does not seem acceptable in this case for several facts. First, the magnitude of the observed sea level increase is significantly larger than the expected windinduced setup, as mentioned above; second, it cannot explain the drop in water temperature measured off Barcelona; third, the wind direction in Valencia and Fos-sur-Mer, before and during the local sea level peaks, is not particularly favourable to coastal water piling, especially in Fos-sur-Mer, where the wind blows from the NE, away from the coast.

\section{3.- Relationship between current intensification and climate change}

Since the intensifications are linked to the prevalence of strong easterlies, typically associated to the presence of lows in the southwestern Mediterranean and highs over Central Europe, it is interesting to try to relate the intensification events to corresponding climatic indices. For this, the dates and intensities of all the recorded events (14) have been plotted on the timeseries of the monthly values of two indices which have been shown to play a role in European climatology. The North Atlantic Oscillation (NAO, Jones et al., 1997) is the most important large-scale mode of climate variability impacting Europe, and it has been correlated to precipitation rates (Hurrell, 1995), Alpine snow cover (Beniston, 1997), thickness of the ozone layer over the continent (Appenzeller et al., 2000) or sea levels in the Mediterranean (Tsimplis et al., 2013; Martínez-Asensio et al., 2014), amongst other variables. The second index, the Western Mediterranean Oscillation (WEMO, Martín-Vide and López-Bustins, 2006) is a regional climatic pattern that has been shown to be better correlated than NAO to different phenomena in the Western Mediterranean region, such as rainfall (Hidalgo-Muñoz et al., 2011) of wave climate (Guizien, 2009).

Although the number of total events (14) is too small to obtain a significant correlation between intensifications and climatic indices, some interesting conclusions can be extracted. There is no obvious relation between the monthly value of the climatic indices and the magnitude of the intensifications. However, most of the events (85\%) were observed during the negative phase of these indices (figure 12, top); regarding the 5 specific events analysed in this paper, 4 were measured during negative WEMO months, whilst each one of them coincided with a negative NAO period. 

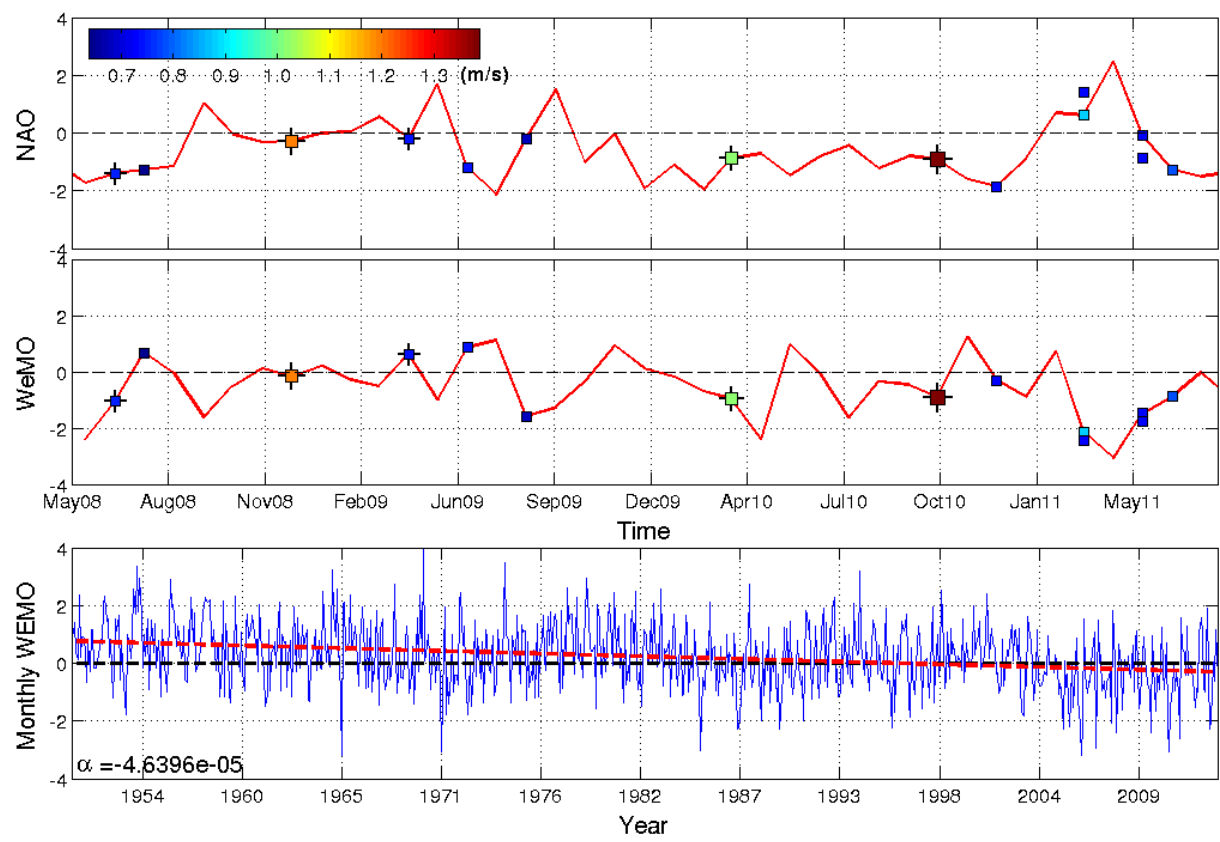

Figure 12: Top) Monthly values of various climatic indices (full line) and observed intensification events in Barcelona. The size and colour of the squares are proportional to the maximum recorded velocity for each event. Squares marked with a cross correspond to the intensifications analysed in this paper. March and May, 2011 presented two events each. Bottom) Monthly WeMO index between 1950 and 2013. The black line corresponds to $\mathrm{WeMO}=0$; the red line shows the trend.

The Western Mediterranean regional character of the WEMO index makes it particularly appropriate to relate to these events. The apparent relationship between the current pulses and this index suggests that, if the negative trend exhibited by the monthly WEMO index since 1950 (figure 12, bottom) is sustained, current intensifications along the Catalan coast and, in particular, on the Barcelona shelf can become more frequent in the future, thus leading to more important and recurrent limitations to ship operations outside the port, under its actual physical configuration, and general maritime activities.

\section{6.- CONCLUSIONS}

Relatively strong flow intensification episodes lasting between 1 and 3 days are observed systematically in the Catalan coast (Northwestern Mediterranean), without a clear seasonal pattern. In addition to their intrinsic scientific interest, these current pulses can also have practical effects for harbours, maritime transport or aquaculture activities. The goal of this study is to attain sufficient knowledge on the influence of the hydrodynamic and meteorological forcings on these events in order to allow its prediction.

Different types of information have been investigated in an attempt to further the knowledge on factors that could generate flow intensifications in this area. Observational meteo-oceanographic data have been combined with numerical products in order to identify local and/or remote forcings. The main mechanism responsible for these intensifications appears to be a combination of wind and topographic effects (increased shelf narrowing due to harbour expansion), although other second-order forcings (e.g., river discharge) also contribute to the flow pulses. The role of the wind was already mentioned in a previous research study (Espino et al., 2011), but no reference was made therein to secondary forcings. 
The analyses of local current and wind data during the events show a high correlation, indicating that the water flow intensifications are induced locally by the strong prevailing easterly or northeasterly winds and possibly enhanced by the proximity of the coastal boundary. Both the overall correlation coefficient and the phase angle are consistent with the generation of local wind-forced currents. In general, the increase in the sea level observed during these events is also compatible in magnitude with the storm surge expected under these winds, supporting the local origin of these intensifications. High-resolution numerical modelling has highlighted the channelling effect due to topographic steering and the narrowing of the coastal shelf, especially in front of the Barcelona harbour where recent port development has further reduced the available shelf width. In the vicinity of the Llobregat rivermouth, the wind-induced intensifications are strengthened by the presence of the freshwater plume, explaining why similar wind episodes do not result in analogous flow pulses. For one of the events (October 2010), a further contribution was due to the passing of a coastally trapped wave, likely generated in the eastern edge of the Gulf of Lion, and propagating southwards over the shelf.

At a synoptic scale, the meteorological conditions during the intensification events show that the typical scenario under which these pulses occur is characterized by the presence of a depression over the Iberian Peninsula and a high pressure centre over Central Europe, following a sustained period (7-14 days) of strong NW-N winds in the Gulf of Lions. However, this general scenario can be altered by the existence of a deep low-pressure centre over the NW Mediterranean, in which case the prevailing winds before the events are easterlies.

The relation between the flow intensifications and the NAO and WeMO climatic indices shows that the current pulses tend to coincide with negative phases of these indices. Although the number of events is too small to allow extracting significant correlations, this comparison introduces the probability that such current accelerations will be more frequent in the future, thus leading to more important and recurrent effects upon maritime uses, including enhanced limitations to ship operations outside the port of Barcelona. Nevertheless, further research is necessary to clarify the exact mechanism by which these disturbances are generated, their frequency in the NW Mediterranean, and their precise contribution to the observed flow intensifications as compared to the local storm surge effects.

\section{7.- ACKNOWLEDGEMENTS}

The authors acknowledge the financial support of the EU's 7th Framework Programme through the projects DANCERS (grant agreement no. 603805) and RISES-AM (Contract FP7-ENV2013-two-stage-603396), together with the PlanWave project (ref. CTM2013-45141-R, MINECO-FEDER Cofund). The support of the Secretaria d'Universitats i Recerca del Dpt. d'Economia i Coneixement of the Generalitat de Catalunya (ref 2014SGR1253) is also acknowledged. Thanks are due to Jordi Cateura and Joan Puigdefàbregas (UPC-BarcelonaTech, Barcelona) for providing data from the XIOM network, and to the Organismo Público Puertos del Estado for tidal and meteorological data from their coastal observational network. Finally, the authors are grateful to Prof. K. Brink (WHOI, Woods Hole) for his interesting input on $\mathrm{CTW}$, and to three anonymous reviewers for their constructive comments.

\section{8.- REFERENCES}


Appenzeller, C., Weiss, A. and Stehelin, J., 2000. North Atlantic Oscillation modulates total ozone winter trends, Geophys. Res. Lett., 27(8), 1131-1134.

Battisti, D.S. and Hickey, B.M., 1984. Application of remote wind-forced coastal trapped wave theory to the Oregon and Washington coasts, J. Phys. Oceanogr., 14, 887-903.

Barnston, A. G., and Livezey, R. E. ,1987. Classification, seasonality and persistence of lowfrequency atmospheric circulation patterns, Mon. Wea. Rev., 115, 1083-1126.

Beniston, M., 1997. Variations of snow depth and duration in the Swiss Alps over the last 50 years: links to changes in large-scale climatic forcings, Climate Change, 36, 281-300.

Bolaños, R., Jordà, G., Cateura, J., López, J., Puigdefàbregas, J., Gómez, J. and Espino, M., 2009. The XIOM: 20 years of a regional coastal observatory in the Spanish Catalan coast, J. Mar. Syst., 77(3), 237-260.

Brink, K.H. and Chapman, D.C., 1985. Programs for computing properties of coastal trapped waves and wind-driven motions over the continental shelf and slope, Technical Report, Woods Hole Oceanogr. Inst., Woods Hole.

Brink, K.H., 1982. A comparison of Long Coastal Trapped Wave Theory with Observations off Peru, J. Phys. Oceanogr., 12, 897-913.

Di Marco, S.F., Howard, M.K., Nowlin, W.D., and Reid, R.O., 2004. Subsurface, high-speed current jets in the deepwater region of the Gulf of Mexico, U.S. Dept. of the Interior, Minerals Management Service, Gulf of Mexico OCS Region, New Orleans, LA. OCS Study MMS 2004022, $98 \mathrm{pp}$.

Echevin, V., Mortier, L., Crépon, M., 2003. Interaction of a coastal current with a gulf: application to the shelf circulation of the Gulf of Lions in the Mediterranean Sea, J. Phys. Oceanogr., 33, 188-206.

Espino, M., López, J., Fernández, J., Grifoll, M. and Sánchez-Arcilla, A., 2011. Episodios de intensificación de corriente en el entorno del puerto de Barcelona, Proc. Jornadas Españolas de Costas y Puertos, Las Palmas de Gran Canaria, Spain.

Fita, L., Romero, R., Luque, A., Emanuel, K. and Ramis, C., 2007. Analysis of the environments of seven Mediterranean tropical-like storms using an axisymmetric, no-hydrostatic, cloudresolving model, Nat. Hazards Earth Syst. Sci., 7, 41-56, doi: 10.5194/nhess-7-41-2007.

Flexas, M., Durrieu de Madron, X., Garcia, M.A., Canals, M., Arnau, P., 2002. Flow variability in the Gulf of Lions during the MATER HFF experiment (March-May, 1997), J. Mar. Syst., 3334, 197-214.

Flexas, M., 2003. Mesoscale variability of the Northern current in the Gulf of Lions and the role of bottom topography, $\mathrm{PhD}$ Thesis, Universitat Politècnica de Catalunya, Barcelona, Spain, 159 pp (http://www.tdx.cat/handle/10803/6386).

Font, J., 1990. A comparison of seasonal winds with currents on the continental slope of the Catalan Sea (Northwestern Mediterranean), J. Geophys. Res., 95(C2), 1537-1545. 
Grifoll, M., Aretxabaleta, A., Espino, M. and Warner, J.C., 2012. Along-shelf current variability on the Catalan inner-shelf (NW Mediterranean), J. Geophys. Res., 117, doi:10.1029/2012JC008182.

Grifoll, M., Aretxabaleta, A.L., Pelegrí, J.L., Espino, M., Warner, J.C. and Sánchez-Arcilla, A., 2013. Seasonal circulation over the Catalan inner-shelf (northwest Mediterranean Sea), J. Geophys. Res: Oceans, 118, 1-14, doi:10.1002/jgrc.20403.

Guizien, K., 2009. Spatial variability of wave conditions in the Gulf of Lions (NW Mediterranean Sea), Vie et Milieu - Life and Environment, 59(3-4), 261-270.

Hidalgo-Muñoz, J.M., Argüeso, D., Gámiz-Fortis, J.R., Esteban-Parra, M.J., Castro-Díez, Y., 2011. Trends of extreme precipitation and associated synoptic patterns over the Southern Iberian Peninsula, J. Hydrology, 409(1-2), 497-511.

Hurrell, J.W., 1995. Decadal trends in the North Atlantic Oscillation: Regional Temperatures and Precipitation, Science, 269, 676-679, doi:10.1126/science.269.5224.676

Ivanov, L.I., and Magnell, B.A., 2012. Classification of strong current events based on Gulf of Mexico BOEM NTL dataset, Proc. Oceans 2012 MTS/IEEE Conference, Virginia, USA, DOI: 10.1109/OCEANS.2012.6404914.

Jones, P.D., Jónsson, T. and Wheeler, D., 1997. Extension to the North Atlantic Oscillation using early instrumental pressure observations from Gibraltar and South-West Iceland, Int. J. Climatol. 17, 1433-1450.

Jordà, G., 2005. Towards data assimilation in the Catalan Continental shelf. From data analysis to optimmization methods, $\mathrm{PhD}$ Thesis, Universitat Politècnica de Catalunya, Barcelona, Spain (http://www.tdx.cat/handle/10803/6392).

Jordà, G. and De Mey, P., 2010. Characterization of error dynamics in a 3D coastal model of the Catalan sea using stochastic modelling, Continental Shelf Research, 30, 419- 441 DOI: 10.1016/j.csr.2009.12.013.

Jordi, A., Orfila, A., Basterretxea, G. and Tintoré, J., 2005. Coastal trapped waves in the northwestern Mediterranean, Cont. Shelf. Res., 25, 185-196.

Kumar, V. and Karnatak, G., 2014. Engineering consideration for cage aquaculture, J. Engineering, 4(6), 11-18.

Kundu, P.K., 1976. Ekman veering observed near the ocean bottom, J. Phys. Oceanog., 6,238242, 1976.

LeBlond, P.H. and Mysak, L.A., 1978. Waves in the ocean, Elsevier, 602 pp.

Liste, M., Grifoll, M. and Monbaliu, J., (2014). River plume dispersion in response to flashflood events. Application to the Catalan coast, Cont. Shelf Res., 87, 96-108, doi: 10.1016/j.csr.2014.06.007.

Llasat, M.C., Turco, M., Quintana-Seguí, P. and Llasat-Botija, M., 2014. The snow storm of 8 March 2010 in Catalonia (Spain): a paradigmatic wet-snow event with a high societal impact, Nat. Hazards Earth syst. Sci., 14, 427-441, doi: 10.5194/nhess-14-427-2014. 
Martín-Vide, J. and López-Bustins, J.A., 2006. The Western Mediterranean Oscillation and rainfall in the Iberian Peninsula, Int. J. Clim., 26(11), 1455-1475.

Martínez-Asensio, A., Marcos, M., Tsimplis, M., Gomis, D., Josey, S. and Jordà, G., 2014. Impact of the atmospheric climate modes on Mediterranean sea level variability, Global and Planetary Change, 118, 1-15, doi: 10.1016/j.gloplacha.2014.03.007.

Palanques, A., Puig, P., Guillén, J., Jiménez, J., Gracia, V., Sánchez-Arcilla, A. and Madsen, O., 2002. Near bottom suspended sediment fluxes on the microtidal low energy Ebro continental shelf (NW Mediterranan Sea). Cont. Shelf Res., 22, 285-303.

Palutikof, J.P., 2003. Analysis of Mediterranean climate data: measured and modelled, in: Bolle, H.J. (ed), Mediterranean climate: Variability and trends. Springer-Verlag, Berlin.

Poulain, P.-M., Bussani, A. , Gerin, R., Jungwirth, R., Mauri, E., Menna, M. and Notarstefano, G., 2013. Mediterranean surface currents measured with drifters: From basin to subinertial scales. Oceanography, 26(1), 38-47, doi:10.5670/oceanog.2013.03.

Romero, R. and Emanuel, K., 2013. Medicane risk in a changing climate, J. Geophys. Res. Atmospheres, 118, 5992-6001, doi: 10.1002/jgrd.50475.

Rubio, A., Arnau, P., Espino, M., Flexas, M., Jordà, G., Salat, J., Puigdefàbregas, J. and Sánchez-Arcilla, A., 2005. A field study of the behaviour of an anticyclonic eddy on the Catalan continental shelf (NW Mediterranean), Progress in Oceanography, 66, 142-156.

Sánchez-Arcilla, A. and Simpson, J., 2002. The narrow shelf concept: couplings and fluxes, Cont. Shelf Res., 22(2), 153-172.

Sánchez-Arcilla, A., Espino, M., Grifoll, M., Mösso, C., Sierrra, J.P., Mestres, M., Spyropoulou, S., Hernáez, M., Ojanguren, A., Garcia Sotillo, M., and Álvarez-Fanjul, E., 2010. Quay design and operational oceanography: the case of Bilbao, Proc. 32nd ICCE, Shanghai, China, doi: 10.9753/icce.v32.structures.51.

Schumann, E.H., 1983. Long-period coastal trapper waves off the southeast coast of Southern Africa, Cont. Shelf. Res., 2(2-3), 97-107.

Schumann, E.H., and Brink, K.H., 1990. Coastal-trapped waves off the Coast of South Africa:Generation, Propagation and Current Structures, J. Phys. Oceanogr., 20, 1206-1218.

Shchepetkin, A. F. and McWilliams, J. C., (2005). The regional oceanic modelling system (ROMS): A split-explicit, free-surface, topography-following-coordinate oceanic model, Ocean Modell., 9(4), 347-404.

Trigo, I.F., Bigg, G.R. and Davies, T.D., 2002. Climatology of cyclogenesis mechanisms in the Mediterranean, Mon. Weather Rev., 130, 549-569.

Tsimplis, M.N., Proctor, R. and Flather, R.A., 1995. A two-dimensional tidal model for the Mediterranean Sea, J. Geophys. Res., 100(C8), 16223-16239, doi: 10.1029/95JC01671.

Tsimplis, M., Calafat, F., Marcos, M., Jordà, G., Gomis, D., Fenoglio-Marc, L., Struglia, M., Josey, S. and Chambers, D., 2013. The effect of the NAO on sea level and on mass changes in the Mediterranean Sea, J. Geophys. Res.:Oceans, 118, 1-9, doi: 10.1002/jgrc.20078. 